\title{
Temporal variations in macroinvertebrate communities from the tributaries in the Three Gorges Reservoir Catchment, China
}

Shiyun Chi ${ }^{1,2^{*}}$, Sixin $\mathrm{Li}^{1,2}$, Sheng Chen ${ }^{1,2}$, Mingxiu Chen ${ }^{1,2}$, Jinxiu Zheng ${ }^{1,2}$ and Juxiang $\mathrm{Hu}^{1,2}$

\begin{abstract}
Background: The seasonal variations in macroinvertebrate communities in tropical, temperate and subarctic regions have been observed and well documented to date, but similar studies conducted in subtropical rivers at the regional scale are relatively rare. In this paper, the macroinvertebrate communities from the main tributaries in the Three Gorges Reservoir Catchment (TGRC) were investigated as a function of the four seasons to explore the temporal variations in macroinvertebrate communities and further tests the temporal stability of certain metrics that are based on macroinvertebrates under a routine bioassessment framework.

Results: The taxa richness reached the highest point in spring, followed by winter, autumn and summer. The taxa Chironomidae, Heptageniidae, Corbiculidae and Baetidae dominated the communities across seasons. The temporal variations in communities were mainly reflected in the changes in taxa proportions between seasons. The percentages of the taxa Heptageniidae and Baetidae were the highest in autumn (normal discharge period) and lowest in summer (high discharge period). The abundance of macroinvertebrates was the lowest in summer, increased in autumn and winter, and then decreased in spring. Natural fluctuations of aquatic ecosystems (temporal effects) resulted in variations that were apparent in macroinvertebrate-based metrics, such as EPT\%, Baetidae\%, Caenidae\%, Ephemerellidae\% and Hydropsychidae\%.

Conclusions: The results of our study demonstrated that the macroinvertebrate communities in the main tributaries of the TGRC varied as a function of seasons. This variation was fundamentally similar to the seasonal patterns in subarctic and temperate streams. Different hydro-morphological characteristics and water quality during the high discharge period (summer), low discharge period (winter) and normal discharge period (spring and autumn) strongly affected the distribution patterns of macroinvertebrate communities. Discharge variation among seasons resulted in seasonal fluctuations in the density of macroinvertebrates. In the TGRC, autumn was the important hatching period for mayflies (Ephemeroptera). The variations in metrics related to macroinvertebrates indicated that temporal effects should not be neglected under a biomonitoring framework in future studies.
\end{abstract}

Keywords: Temporal variations, Macroinvertebrate communities, Three gorges reservoir catchment (TGRC), Tributaries

\section{Background}

Macroinvertebrates are ubiquitous and diverse, allow for the detection of a variety of perturbations in aquatic systems, and have relatively long life cycles when compared to planktons; these characteristics make temporal scales

\footnotetext{
*Correspondence: 58249448@qq.com; chishiyun@gmail.com

${ }^{1}$ Key Laboratory of Ecological Impacts of Hydraulic-projects and Restoration of Aquatic Ecosystem, Ministry of Water Resources, Wuhan 430079, People's Republic of China

${ }^{2}$ Institute of hydro-ecology, Ministry of Water Resources and Chinese Academy of Sciences, Wuhan 430079, People's Republic of China
}

of macroinvertebrate population response an appropriate indicator for disturbance responses [1-4]. Although macroinvertebrates are usually used as bio-indicators in environmental or ecological assessments and present several advantages compared to other aquatic organisms, they are limited by various drawbacks and are influenced by human stress and natural factors such as hydrological regime, water temperature, light level, water chemistry, food resources and habitat heterogeneity; these factors present seasonal variations in communities due to changes in species related to life history strategy [5-10]. 
Nearly all facets of the life history of macroinvertebrates, and consequently their distribution and abundance, are influenced by water temperature, substrate type and composition, hydraulic conditions and food availability. In the natural aquatic system, the relative importance of the facets that affect macroinvertebrates and the exact pattern of seasonal variation in communities differ among study cases or geographic location $[4,11]$. Therefore, seasonal changes in macroinvertebrate assemblages can be large in some systems while small in others [12]. Accordingly, the seasonal effects on macroinvertebrate community composition are important, should not be neglected and should be taken into account for biomonitoring purposes $[13,14]$. In tropical, temperate and subarctic river or stream systems, seasonal variations in macroinvertebrate assemblages have been observed and well documented [8, 15-30]. However, most of these investigations were confined to streams or rivers in temperate and tropical areas, and subtropical rivers on the regional scale have received much less attention [31, 32].

In China, investigations or studies related to the seasonal variation in macroinvertebrate communities primarily involved a single waterbody, and few study cases were conducted in multiple waterbodies on a climatic regional scale. The seasonal variations in density, biomass, and diversity or taxa richness of macroinvertebrates were usually simply described or analyzed, and the conclusions varied among different study cases or bodies of water within the same regional or climatic zone. These conflicting results produced uncertainty over the bioassessment confidence and precision when assessing the aquatic ecological status with macroinvertebrate-based metrics [33-38]. In this paper, with the background of carrying out the National Water Issues Three Gorges Reservoir Special project during the Eleventh Five-Year Plan, the 27 main tributaries in the Three Gorges Reservoir Catchment (TGRC) were investigated from 2010 to 2011 to explore the temporal variations in macroinvertebrate communities on a regional scale. The objective of this study was to determine whether the macroinvertebrate communities from the tributaries in the TGRC varied as a function of seasons and to further test the temporal stability of certain metrics based on macroinvertebrates under a routine bioassessment framework. This study will provide a deeper understanding of the aquatic status in the future.

\section{Methods}

Study area

The TGRC lies in a $600-\mathrm{km}$ mountain zone between the cities Chongqing and Yichang, a transitional zone from the Tibetan Plateau to rolling hills and plains. This zone has a humid subtropical monsoon climate and an elevation of $800-2000 \mathrm{~m}$. The TGRC has four distinct seasons: warm winters, early springs, hot and dry summers, and rainy, humid and foggy autumns. The mean annual temperature is $16.5-19{ }^{\circ} \mathrm{C}$, and the mean annual precipitation is approximately $1100-1200 \mathrm{~mm}$. The rainfall in this region is abundant but unevenly distributed on the temporal and spatial scale. For instance, the precipitation from April to October accounts for over 80\% of the total annual rainfall (Fig. 1). The soil types comprise red soil, yellow soil, and mountain yellow soil. With the Three Gorges Dam (TGD) fully functional in 2010, the water level of the reservoir ranged from $145 \mathrm{~m}$ to $175 \mathrm{~m}$, while many bays formed at the mouths of the many tributaries that ran into the Yangtze River [39-41]. In this study, four surveys

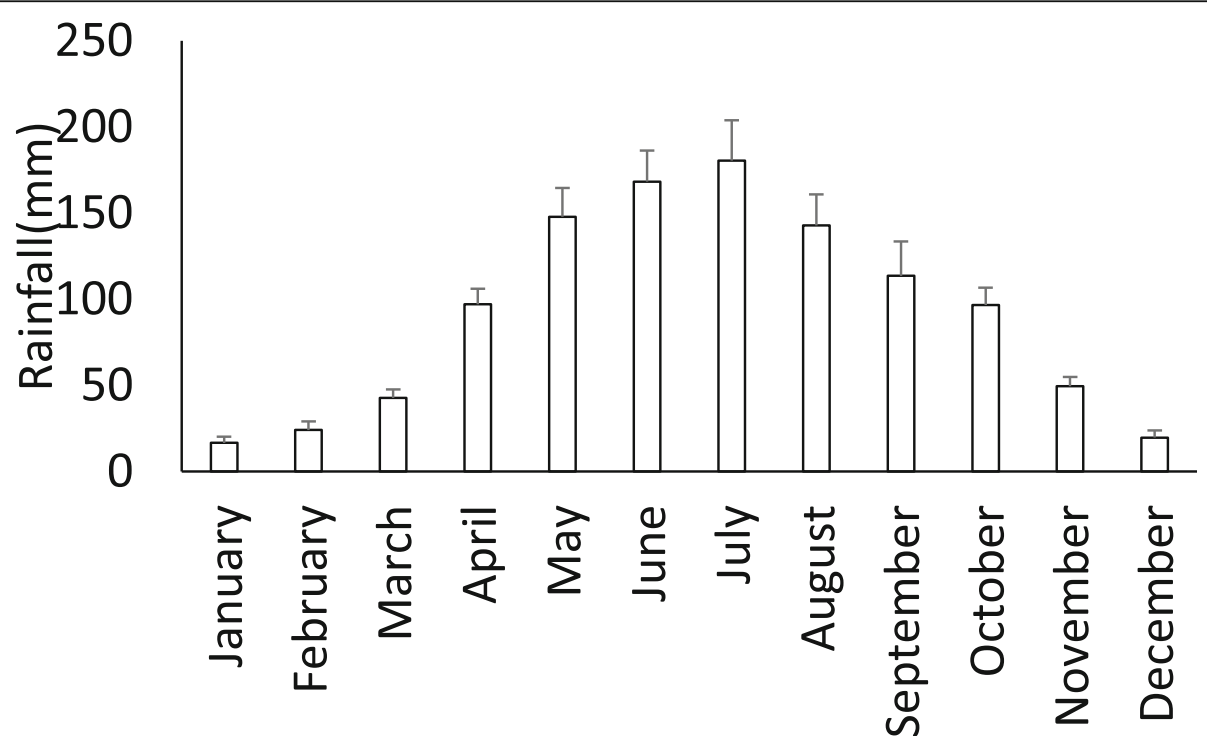

Fig. 1 The average rainfall of each month in the TGRC from 1951 to 2010. Note: (Spring: February-April; Summer: May-July; Autumn: August-October; Winter: November-January) 
were conducted in the 27 main tributaries of the TGRC, and all sampling sites were visited during each of the four seasons. The spring data were collected in April 2010, the summer data were collected in June 2011, the autumn data were collected in August 2010, and the winter data were collected in January 2011 (Additional file 1: Appendix 1 and Fig. 2).

\section{Data collection}

In each tributary, two to four sampling sites in principle were set up from upstream to downstream. Macroinvertebrate samples were randomly collected in riffle/run habitats by a modified Surber sampler $\left(0.1575 \mathrm{~m}^{2}, 500 \mu \mathrm{m}\right.$ mesh). At each sampling site, two nets were collected and merged to represent a single sample (total area $0.315 \mathrm{~m}^{2}$ ). During the sampling period, some samples were missing due to the absence of macroinvertebrates. A total of 241 samples were collected during the survey period. Samples were placed into plastic wide-mouth bottles and fixed with $4 \%$ formalin. The fixed samples were then transported to the laboratory after sorting for identification with an Olympus microscope (BH-2, Japan) and Leica stereomicroscope (EZ4D, Germany) [40]. The family level is regarded to be the most sensitive when detecting community change; it also has a reasonable trade-off between cost and discrimination, is achievable for most taxa, and can be consistent among laboratories [4, 7, 12, 42, 43]. Moreover, identification to the family level is most appropriate when samples contain many early instar larvae and are thus difficult to identify to lower taxonomic levels [12]. Therefore, in our study, all specimens were identified to or grouped into family levels. Water temperature (WT), dissolved oxygen (DO), oxidation-reduction potential (ORP), and conductivity (Cond) were measured in situ with a multi-parameters analyzer (YSI 6600). Secchi depth (SD) was measured in situ by a Secchi disc for analyzing water transparency. The contents of chlorophyll a (Chl a) in waterbodies were measured by ethyl alcohol spectrophotometry in the laboratory.

\section{Data treatment and analysis}

The macroinvertebrate family-level richness (taxa richness), Shannon-Wiener index and density (ind $\mathrm{m}^{-2}$ ) were calculated for each sampling site. Biodiversity was described with the Shannon-Wiener index $\left(\mathrm{H}^{\prime}\right): \mathrm{H}^{\prime}=-\sum_{1}^{n}$ $P_{i} \ln P_{i}$, where $P_{i}$ is the relative abundance of the species $\mathrm{i}$; $P_{i}=N_{i} / \mathrm{N}$, where $N_{i}$ is the density of the species $\mathrm{i}, \mathrm{n}$ is the number of species and $\mathrm{N}$ is the total density of the macroinvertebrates [44]. Multivariate statistical analyses were

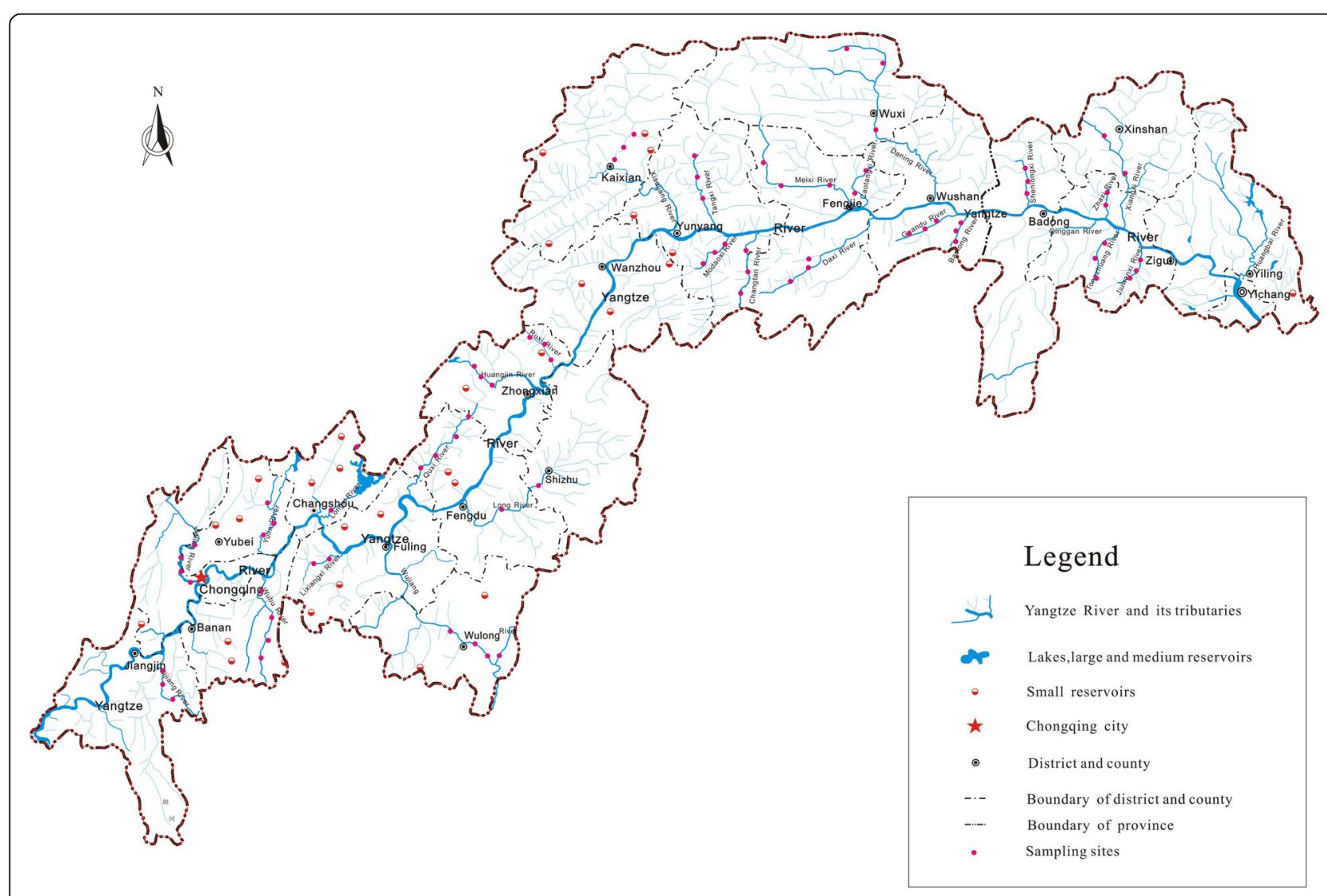

Fig. 2 Locations of sampling sites in the TGRC 
performed using MjM PC-Ord version 6.0 software. For visually displaying the differences among seasonal communities, non-metric multidimensional scaling (NMDS) was used to delineate the ordination as this technique was found to be most robust when analyzing community data $[2,45]$. Rare taxa provide redundant information for ordinations, and the final stress of an NMDS ordination increases with sample size; therefore, prior to ordinations, taxa occurring in $<5 \%$ of samples were excluded to reduce these biases $[2,12]$. Prior to multivariate analysis, the abundance data were $\log (x+1)$ transformed to reduce the effect of extremely abundant taxa [46]. The multivariate analyses were performed with the default distance measure of Bray-Curtis similarity. Significance tests for differences in macro-invertebrate assemblages among seasons (spring, summer, autumn, and winter) were undertaken using Multi-Response Permutation Procedures (MRPP). MRPP is a non-parametric procedure that is designed to test for differences in multivariate responses among groups and does not require multivariate normality and homogeneity of variance, which are seldom met with ecological community data [47]. The indicator taxa (families) from different seasons were identified using the Indicator Species Analysis (ISA) [48]. The ISA measures the fidelity of taxa occurrence within groups with indicator values (IV) for species in each group; these values range from 0 (no group indicator) to $100 \%$ (perfect group indicator). The statistical significance for each species was tested with a Monte Carlo randomization technique. Moreover, the metrics based on taxa composition and abundance from the different seasons were compared using a Kruskal-Wallis test due to the heteroscedasticity of the data. This test assessed the temporal stability under a bioassessment framework. Furthermore, the macroinvertebrate density, taxa richness and Shannon-Wiener index as a function of seasons were also compared using the Kruskal-Wallis test to explore the temporal dynamics with seasons [49]. The Kruskal-Wallis tests were conducted by SPSS version 20.0 software.

\section{Results}

Water characteristics in the main tributaries

In the main tributaries of TGRC, the physical and chemical properties of waterbodies changed with seasons. With the exception of $\mathrm{pH}$, the differences in SD, WT, Chl a, DO, ORP and Cond were found to be significant among seasons (Kruskal-Wallis test, $p<0.01$ ). The waterbodies had the lowest transparency in summer and the highest transparency in winter. In summer and autumn, the waterbodies had higher water temperatures. The contents of chlorophyll a were highest in spring and lowest in winter. In spring and summer, the waterbodies had relatively higher dissolved oxygen concentrations, and in autumn and winter, the waterbodies had relatively higher values of ORP when compared to the other seasons. The values of Cond were the lowest in spring while the highest in summer (Table 1).

\section{Macroinvertebrate community composition}

During the four seasons investigated, a total of 87 taxa (family) were recorded in the 27 main tributaries of the TGRC (Additional file 1: Appendix 2). The taxa richness found during the four seasons varied (61 families in spring, 40 families in summer, 47 families in autumn, and 52 families in winter). The 10 most numerically abundant taxa in each season are shown in Table 1. The taxa Chironomidae, Heptageniidae and Baetidae were very common and abundant in all four seasons and occupied the dominant positions in the macroinvertebrate communities. The taxon Corbiculidae always appeared in the list of the 10 most numerically abundant taxa but with relatively small proportions. When combined with data from all four seasons, the taxa Chironomidae, Heptageniidae, Baetidae, Caenidae, Lymnaeidae, Tubificidae, Leptophlebiidae, Corbiculidae, Hydropsychidae and Viviparidae were the dominant taxa in the 27 main tributaries of the TGRC (Table 2).

\section{Temporal variation in communities}

Prior to the NMDS analysis, rare taxa (occurrence at $<5 \%$ of sites) were removed from the family abundant data to reduce the ordination biases. The three-dimensional stress that was associated with the NMDS ordination based on the $\log (\mathrm{x}+1)$ transformed abundant data was 0.1534 , and thus indicated that the plot gave a fair representation of the associations among samples. In the NMDS biplot (Fig. 3), the four-season sample groups were separated from each other. According to the results of the MRPP

Table 1 Summary of the water parameters of the 27 main tributaries of TGRC

\begin{tabular}{llllllll}
\hline Seasons & $\mathrm{SD}(\mathrm{cm})$ & $\mathrm{WT}\left({ }^{\circ} \mathrm{C}\right)$ & $\mathrm{pH}$ & $\mathrm{Chl} \mathrm{a}(\mu \mathrm{g} / \mathrm{l})$ & $\mathrm{DO}(\mathrm{mg} / \mathrm{l})$ & $\mathrm{ORP}(\mathrm{mv})$ & $\mathrm{Cond}(\mu \mathrm{S} / \mathrm{cm})$ \\
\hline Spring & $131.69 \pm 112.87^{\mathrm{b}}$ & $15.96 \pm 1.84^{\mathrm{b}}$ & $8.31 \pm 0.48^{\mathrm{b}}$ & $10.53 \pm 25.06^{\mathrm{c}}$ & $9.00 \pm 2.04^{\mathrm{b}}$ & $145.85 \pm 45.44^{\mathrm{a}}$ & $134.21 \pm 41.85^{\mathrm{a}}$ \\
Summer & $57.64 \pm 49.24^{\mathrm{a}}$ & $22.35 \pm 3.43^{\mathrm{d}}$ & $8.24 \pm 0.28^{\mathrm{a}}$ & $5.82 \pm 10.26^{\mathrm{b}}$ & $8.82 \pm 1.89^{\mathrm{b}}$ & $143.85 \pm 100.6^{\mathrm{a}}$ & $305.09 \pm 141.79^{\mathrm{c}}$ \\
Autumn & $136.64 \pm 52.03^{\mathrm{c}}$ & $20.02 \pm 2.87^{\mathrm{c}}$ & $8.23 \pm 0.38^{\mathrm{ab}}$ & $7.76 \pm 10.21^{\mathrm{c}}$ & $7.26 \pm 1.49^{\mathrm{a}}$ & $165.75 \pm 22.62^{\mathrm{b}}$ & $288.23 \pm 78.94 \mathrm{~b}^{\mathrm{c}}$ \\
Winter & $239.69 \pm 73.18^{\mathrm{d}}$ & $9.86 \pm 3.30^{\mathrm{a}}$ & $8.26 \pm 0.32^{\mathrm{ab}}$ & $1.15 \pm 2.03^{\mathrm{a}}$ & $7.58 \pm 0.77^{\mathrm{c}}$ & $154.12 \pm 38.02^{\mathrm{b}}$ & $285.86 \pm 66.19 \mathrm{~b}^{\mathrm{c}}$ \\
Chi-Square & 163.955 & 420.838 & 5.844 & 174.943 & 119.062 & 33.568 & 270.117 \\
p-value & $<0.001$ & $<0.001$ & 0.119 & $<0.001$ & $<0.001$ & $<0.001$ & $<0.001$ \\
\hline
\end{tabular}

Note: Different letters represent significant differences, same letters represent nonsignificant differences 
Table 2 Proportion of individuals of the 10 most numerically abundant macroinvertebrate taxa within the 27 main tributaries of TGRC

\begin{tabular}{|c|c|c|c|c|c|}
\hline \multirow[t]{2}{*}{ Taxon } & \multicolumn{5}{|c|}{$\%$ of total individuals } \\
\hline & Spring & Summer & Autumn & Winter & Total \\
\hline Chironomidae & 24.55 & 21.22 & 16.40 & 17.29 & 19.80 \\
\hline Heptageniidae & 17.29 & 14.37 & 22.05 & 15.56 & 17.24 \\
\hline Baetidae & 16.36 & 12.05 & 31.52 & 23.26 & 20.77 \\
\hline Caenidae & 6.17 & 4.08 & & & 3.23 \\
\hline Lymnaeidae & 3.97 & & & & 2.84 \\
\hline Tubificidae & 3.67 & 9.10 & & 2.51 & 4.18 \\
\hline Ephemeridae & 2.59 & 4.92 & & & \\
\hline Leptophlebiidae & 2.58 & 2.87 & 2.36 & & 2.54 \\
\hline Corbiculidae & 2.22 & 2.68 & 2.71 & 2.66 & 2.57 \\
\hline Tipulidae & 1.90 & 2.83 & & 3.86 & \\
\hline Hydropsychidae & & 5.00 & 4.80 & 5.68 & 4.23 \\
\hline Elmidae & & & 1.86 & & \\
\hline Viviparidae & & & 1.80 & 5.75 & 2.73 \\
\hline Potamanthidae & & & 1.58 & & \\
\hline Mytilidae & & & & 3.11 & \\
\hline Ephemerellidae & & & & 2.58 & \\
\hline
\end{tabular}

tests (Table 3), the differences in communities from the four seasons were very significant $(p<0.05)$, thus indicating that the macroinvertebrate taxa composition changed with seasons. In light of the results of the ISA analysis, the spring group was characterized by the taxa Caenidae, Ceratopogonidae, unidentified Diptera and Chironomidae. The taxon Planorbidae was the predominant taxa of the summer group. The taxa Baetidae, Ecnomidae, Heptageniidae and Leptoceridae characterized the autumn group. The indicator taxa in the winter group were
Table 3 Pairwise comparisons among four season macroinvertebrate communities using the multi-response permutation procedure (MRPP)

\begin{tabular}{llll}
\hline Pair groups & $\mathrm{T}$ & $\mathrm{A}$ & $\mathrm{P}$ \\
\hline Autumn vs Summer & -11.6299 & 0.0253 & $<0.0001$ \\
Autumn vs Spring & -6.9442 & 0.0153 & $<0.0001$ \\
Autumn vs Winter & -3.7870 & 0.0075 & 0.0033 \\
Summer vs Spring & -7.5393 & 0.0167 & $<0.0001$ \\
Summer vs Winter & -12.2007 & 0.0254 & $<0.0001$ \\
Spring vs Winter & -7.6457 & 0.0158 & $<0.0001$ \\
\hline
\end{tabular}

Ephemerellidae, Tipulidae, Mytilidae, Hydropsychidae and Limnephilidae (Table 4).

\section{Temporal variation in metrics associated with taxa composition, biodiversity and abundance}

Among the metrics associated with taxa composition, EPT\% (Percentages of Ephemeroptera, Plecoptera and Trichoptera), Baetidae\%, Caenidae\%, Ephemerellidae\% and Hydropsychidae\% showed significant differences between seasons (Kruskal-Wallis test, $p<0.05$ ). EPT\% and Baetidae\% reached their highest values in autumn, Caenidae\% reached their highest values in spring, and Ephemerellidae $\%$ and Hydropsychidae\% reached their maximum values in winter. The other 5 metrics, including Chironomidae\%, Heptageniidae\%, Tipulidae\%, aquatic insects\% and molluscs\%, did not show significant differences between seasons (Kruskal-Wallis Test, $p>0.05$ ) (Fig. 4). The taxa richness and Shannon-Wiener index showed strong seasonal stability (Fig. 5). Moreover, the densities of macroinvertebrates had significant temporal variations and reached their minimum values in summer and maximum values in winter (Fig. 6).

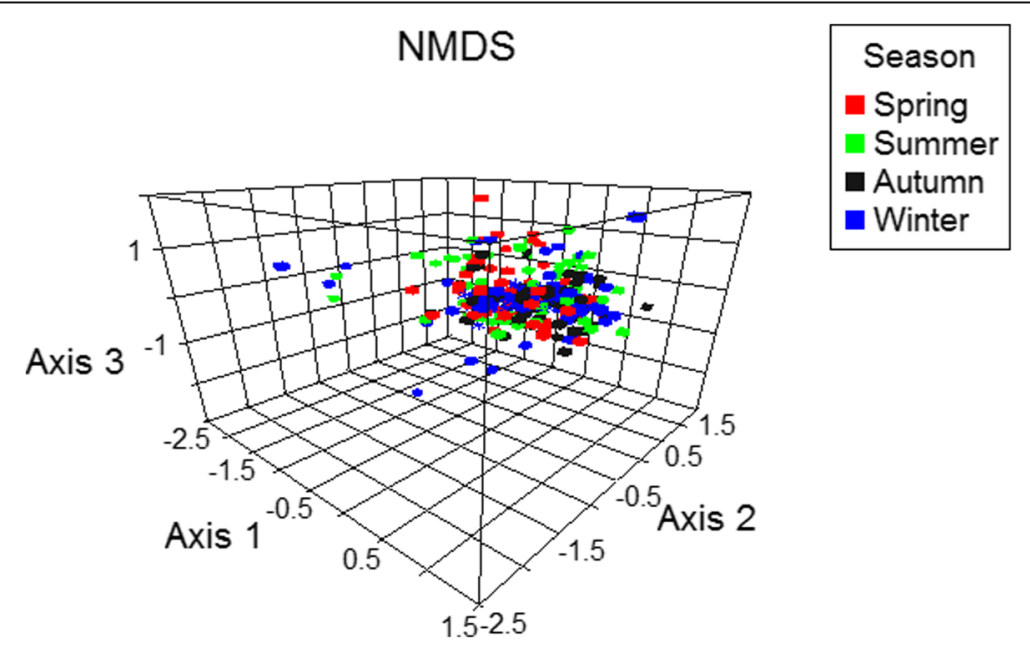

Fig. 3 Ordination of sampling sites based on macroinvertebrate data. Sites were assigned to four season groups. Stress value $=0.1534$ 
Table 4 Indicator taxa and indicator values (IV) identified for four season data using ISA analysis with Monte Carlo permutation test (4999 runs)

\begin{tabular}{llll}
\hline Family name & Seasons & Indicator Value (IV) & $p$-value \\
\hline Caenidae & Spring & 25.5 & 0.0002 \\
Ceratopogonidae & Spring & 17.8 & 0.0002 \\
Unidentified Diptera & Spring & 18.8 & 0.0002 \\
Chironomidae & Spring & 28.1 & 0.0258 \\
Planorbidae & Summer & 12.1 & 0.0018 \\
Baetidae & Autumn & 30.3 & 0.0004 \\
Ecnomidae & Autumn & 11.8 & 0.0006 \\
Heptageniidae & Autumn & 25.8 & 0.0286 \\
Leptoceridae & Autumn & 6.9 & 0.0442 \\
Ephemerellidae & Winter & 23.8 & 0.0014 \\
Tipulidae & Winter & 22.1 & 0.002 \\
Mytilidae & Winter & 11 & 0.0194 \\
Hydropsychidae & Winter & 20.7 & 0.0282 \\
Limnephilidae & Winter & 7.5 & 0.0398 \\
\hline
\end{tabular}

Indicator species $(p \leq 0.05)$

\section{Discussion}

The results of our study showed that the macroinvertebrate communities in the 27 main tributaries of the TGRC varied with seasons. Among the four seasons, the taxonomic richness that was determined on the family level reached the highest point in spring, followed by winter, autumn and summer. Seasonal patterns of macroinvertebrates are largely a reflection of the seasonal trends of the predominant organisms [50]. The top 10 predominant taxa compositions showed distinct temporal variations as a function of seasons. Among them, the taxa Chironomidae, Heptageniidae, Corbiculidae and Baetidae were predominant across the four seasons and thus showed a certain extent of temporal stability. The temporal variations in communities were mainly reflected by changes in taxa proportions between seasons, which were confirmed by the results of the MRPP and ISA analyses. Moreover, the ordination plots based on NMDS analysis also revealed four distinct seasonal assemblages based on taxonomic composition. Studies showed that the taxonomic level decided the direction and the amount of seasonal variations in macroinvertebrate communities [43], and the use of the family level contributed to a decrease in temporal variation [7]. This is because representatives of families are likely to be present throughout the year, while lower taxa may be present at different times of the year due to their life cycles [43]. However, in our study, temporal variations in macroinvertebrate communities were still detected at the family level.

Strong seasonal variation among macroinvertebrates was confined primarily to streams at low altitudes $(600-800 \mathrm{~m})$ with the greatest monsoon rainfall [51].
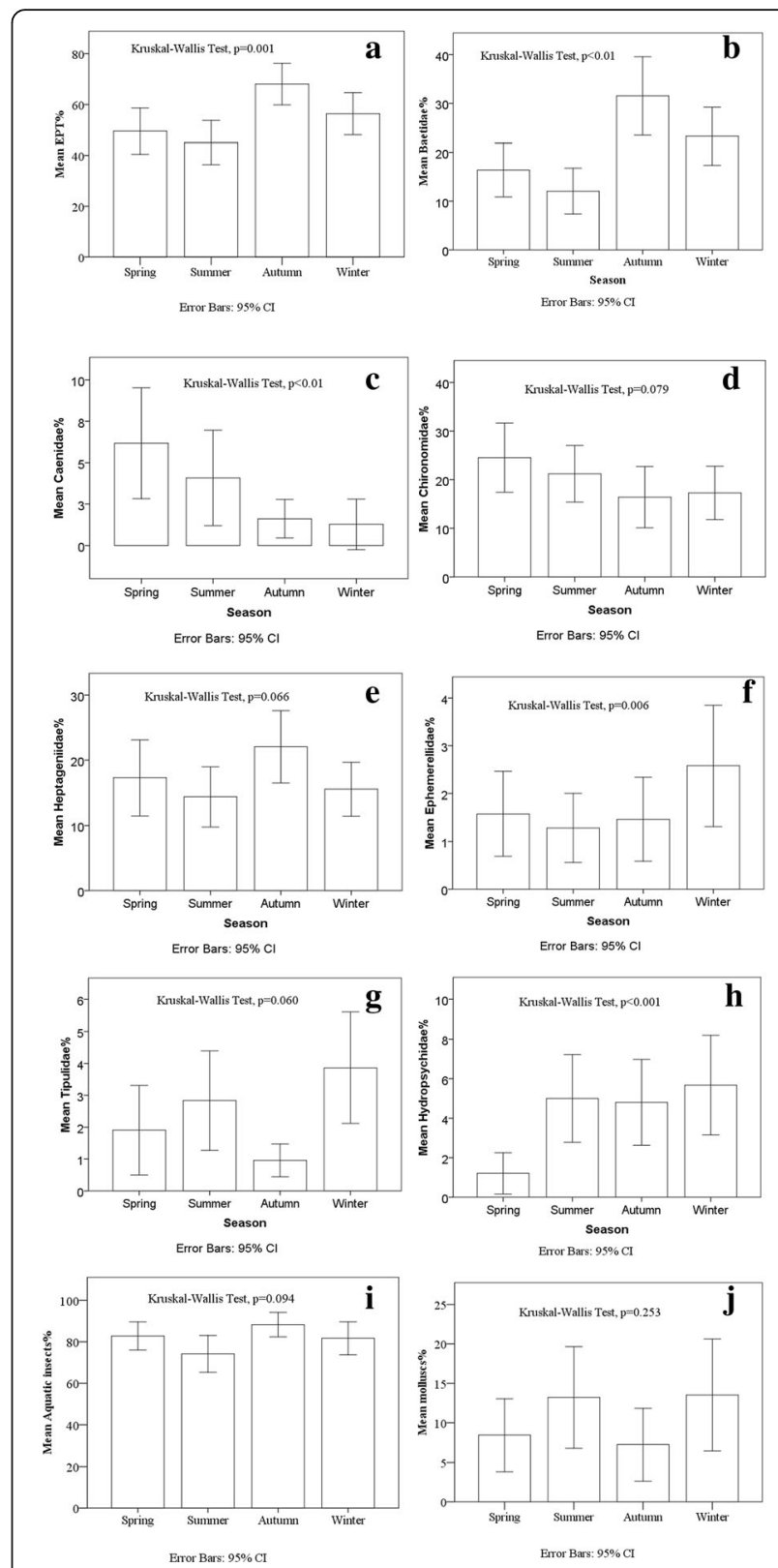

Fig. 4 Metrics of macroinvertebrate communities related to taxa composition in four seasons during 2010-2011. Results of Kruskal-Wallis tests were shown in the plots. Note: the percentages of the dominant taxa between seasons with IV >20 were shown in the plots

Meanwhile, hydro-morphological characteristics and the water quality of aquatic systems largely determined changes in macroinvertebrate communities [17]. In the TGRC, the tributaries with elevations of 800-2000 m exhibited different hydro-morphological characteristics and water quality during the high discharge period (summer), the normal discharge period (spring and autumn) and the low discharge period (winter) [52, 53]. These differences strongly affected the distribution patterns of 

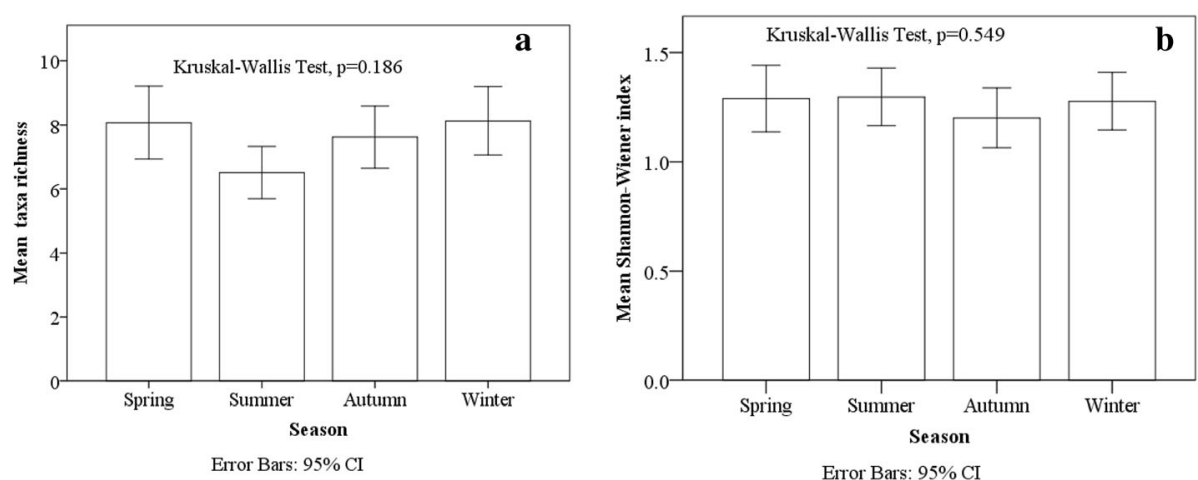

Fig. 5 Metrics of macroinvertebrate communities related to biodiversity in four seasons during 2010-2011. Results of Kruskal-Wallis tests were shown in the plots

macroinvertebrate communities among different seasons (Table 1) because, during the wet season, high discharge usually triggers the drift behavior of some species and enhances the colonization of new species, thus bringing out the temporal variations in the abundance of the major taxa [17].

Studies showed that the highest concentrations of individuals from most major taxonomic groups were found during the egg hatching season [6]. Mayflies (Ephemeroptera) were more abundant during the dry season and decreased during the wet season as a result of being washed away [17]. The rational explanation for this phenomenon is that the dry season, with low current and relatively high water temperature, is often the major hatching period for mayflies and thus results in the rapid growth in individuals [17]. Our study showed that the percentage of the taxa Heptageniidae and Baetidae, which were involved in the top 10

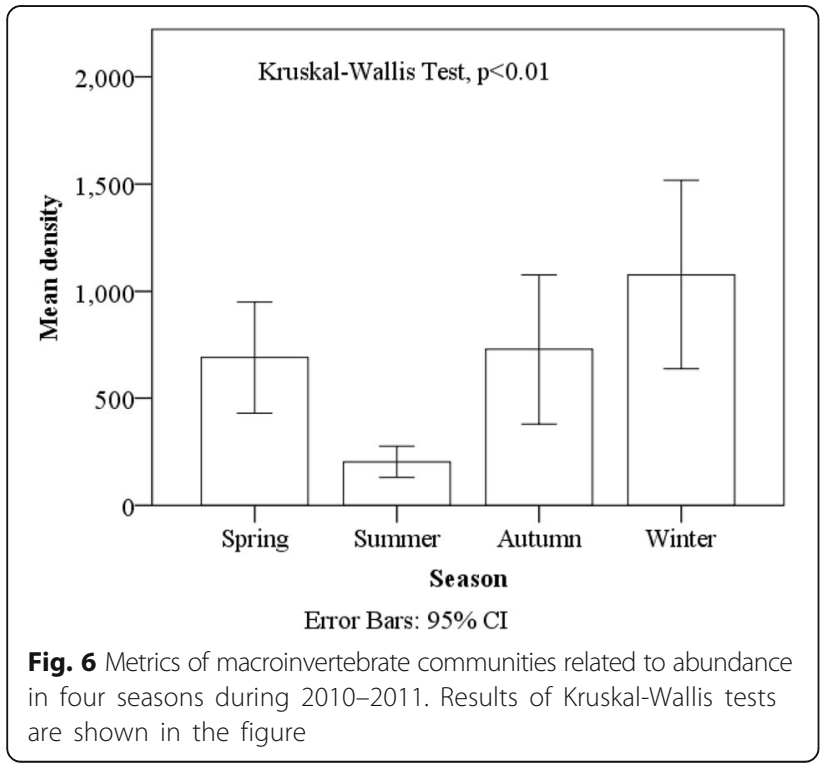

predominant taxa composition, was highest $(53.57 \%)$ in autumn (the normal discharge period) and lowest $(26.42 \%)$ in summer (the high discharge period). Our results were slightly different from the previously described observational results and inferred that autumn was the important hatching period for mayflies.

Seasonal patterns in climate, such as precipitation and insolation, result in within-year changes in the flow and temperature of aquatic systems. These changes greatly influence the timing of emergence, reproduction, growth and development of many aquatic macroinvertebrates and, in turn, influence the seasonal replacement of organisms [54]. Thus, among the numerous environmental conditions, discharge and water temperature are often considered the important factors that contribute to the marked seasonality in assemblage composition $[7,24,25$, 27, 55]. According to the theory "intermediate disturbances", the season variations in discharge and water temperature enhance species richness and maintain maximum species density. Discharge variation as a function of seasons contributes to the changes of available habitats by affecting areas of wetted perimeter in river systems, while water temperature variation as a function of seasons results in disturbances to many species with different life history strategies [24]. During the wet season, high discharge events can cause severe population losses and changes in the community composition and structure of macroinvertebrates; spate-induced disturbances also induce high variation in wet-season samples [31, 32]. The fluctuations in densities of macroinvertebrates are associated with the unpredictable floods and different life histories of most macroinvertebrates in tropical areas. At temperate latitudes, loss of organisms through flushing during the spring thaw or summer emergence of aquatic insects caused the density fluctuations of macroinvertebrates; in the tropical areas, however, the interruption of flow or low flow resulted in a marked reduction in density [17]. Streams in monsoonal environments are subject to 
extreme seasonal variation in flow. Predictable floods and spates in these areas are qualified as disturbances due to their large magnitude and geomorphological effect [31]. In the TGRC tributaries, which were located in a subtropical region with altitudes from 800 to $1000 \mathrm{~m}$, discharge variation among seasons was still an important factor that caused the density fluctuations in macroinvertebrates. The discharge of these tributaries is often large due to floods that occur frequently in summer, and the density of macroinvertebrates in summer declined by scouring when compared to other seasons. The significant differences in community composition among seasons reflected the different life history strategies of most macroinvertebrate taxa [56].

Temporal changes in macroinvertebrate composition have been related to life history patterns in the community, and this relationship has been hypothesized to have evolved in response to food availability and seasonal changes in physicochemical factors [9]. Seasonal abundance of food could strongly influence the life cycles of the aquatic community and could result in the seasonal variation in macroinvertebrate community composition $[6,57]$. The variations of food abundance as a function of season can result in significant seasonal variations in the abundance of certain taxa [7]. In tropical areas, the end of each dry season and the start of the rainy season experience the accumulation of allochthonous materials such as leaves and twigs. The accumulation of these materials in riverbeds provides shelters, or habitats, and food sources for macroinvertebrates [17]. In the TGRC tributaries, leaves and twigs from mountain trees along the riverbeds served as important shelters for some taxa, especially mayflies and caddisflies, and the attached algae were important food resources for scrapers. It was possible that these factors were the reasons why the percentages of EPT taxa were high in all seasons and exhibited significant temporal variations (Fig. 4a). In subarctic and temperate streams, the abundance of macroinvertebrates was low in mid-summer, increased in late summer and autumn due to recruitment from the hatching and growth of shredders that followed autumnal leaf input, and sharply declined in spring due to associated adult emergence [19]. In our study, the abundance of macroinvertebrates was the lowest in summer, increased in autumn and winter, and then decreased in spring. The temporality of macroinvertebrates in these subtropical tributaries was fundamentally similar to the seasonal patterns in subarctic and temperate streams. In subtropical areas, such as Georgia, USA, the number of EPT taxa showed high variation among seasons, while chironomid richness demonstrated decent seasonal stability [2]. In tropical forest streams, such as those in Malaysia, relatively more EPT individuals were found during the dry season when compared to the wet season and the seasonality impact on EPT taxa was extremely evident [58]. In this study, the percentages of EPT taxa, some mayflies such as Baetidae, Caenidae and Ephemerellidae, and caddisflies such as Hydropsychidae showed significant temporal variation $(p<0.01)$. The percentage of Chironomidae, however, displayed nonsignificant temporal variation $(p=0.079)$. This finding was related to the seasonal changes in the life cycles of particular taxa, resulting in the seasonality changes in relative abundances [59]. In subtropical monsoonal climate streams, small body sizes, short life cycles and continuous reproduction could be important strategies that ensure the rapid resilience and persistence of macroinvertebrate assemblages through time [31]. These factors may explain why the percentage of Chironomidae abundance showed nonsignificant temporal variation in the TGRC.

Macroinvertebrates are sensitive to watershed conditions and exhibit sufficient stability in assemblage structure over time; these characteristics make them useful as long-term monitors of aquatic system health and indicators of water quality [3]. Seasonal changes in macroinvertebrate taxon abundances that are related to life history introduce temporal variation into macroinvertebrate community structure and can potentially confound bioassessments [56]. In bioassessment framework, seasonal variability should be taken into account for providing acceptable levels of confidence and precision [14, 60]. Some metrics did not change significantly with seasons because certain representative species from different orders were present in all seasons [13]. Furthermore, certain metrics with pronounced seasonal variability lead to the greatest criticism in biomonitoring [61]. Ignoring natural seasonal variability in metrics can confound the detection of anthropogenic environmental change and affect the consistency and efficacy of metrics $[2,4,6$, 62]. In the streams of central Europe, a region dominated by a temperate climate, most metrics based on macroinvertebrates exhibited significant differences among seasons [6]. In the streams located in central western Georgia, USA, an area characterized by subtropical climate, the metrics related to compositional and functional feeding group measurements also showed high seasonal and annual variation [2]. In this paper, natural fluctuation of aquatic ecosystems (temporal effects) resulted in variations in metrics such as EPT\%, Baetidae\%, Caenidae\%, Ephemerellidae\% and Hydropsychidae\%. These results indicate that seasonal effects should not be neglected under biomonitoring framework.

In climate regions with relatively high seasonal environmental variability or complex climatic patterns, the macroinvertebrate fauna was always characterized by the stochastic, unstable community structure in aquatic systems; within these systems, organisms had fast growth and high colonization capacity, and showed strong temporal variation or seasonality $[31,55]$. For instance, the 
species richness and abundance were significantly higher during the dry season than during the wet season in tropical streams [22, 58]. Considerable seasonal and annual variations were observed in the densities of the major macroinvertebrate groups in the arctic and alpine river systems [63]. In the temperate zone, macroinvertebrate communities varied seasonally and displayed significant seasonality [64]. In the TGRC tributaries, Chironomidae, Heptageniidae and Baetidae were the three most numerous families across seasons, but their changes in abundance as a function of season could induce strong temporal variations among all macroinvertebrates. This would cause temporal variations in a series of metrics based on macroinvertebrates, and further demonstrates that the seasonal effects in biomonitoring studies should not be ignored in future studies. In the subtropical monsoonal climate streams of South America, community composition and abundance of macroinvertebrates differed significantly between seasons [31]. This variation was supported by our results, which showed that the effect of seasons on macroinvertebrate communities were very strong in subtropical monsoonal areas.

\section{Conclusion}

The temporal variations in macroinvertebrate communities in the main tributaries of the TGRC were significant, and Chironomidae, Heptageniidae, Corbiculidae and Baetidae dominated the communities across seasons. The changes in taxa proportions caused the temporal variations in the communities, and the temporal variations could be detected at the family level. The different hydro-morphological characteristics and water quality during different seasons strongly affected the distribution patterns of macroinvertebrate communities, and autumn was the important hatching period for mayflies in the TGRC. Discharge variation among seasons was an important factor for the density fluctuations of macroinvertebrates. In the TGRC tributaries, the temporal variation patterns of macroinvertebrates were fundamentally similar to the seasonal patterns in subarctic and temperate streams. Natural fluctuations in aquatic ecosystems (temporal effects) resulted in variations in some macroinvertebrate-based metrics and indicated that seasonal effects should not be neglected under biomonitoring framework. Furthermore, our results also supported the observation that seasonal effects on macroinvertebrate communities were very strong in subtropical monsoonal areas.

\section{Additional file}

Additional file 1: Appendix 1. Characteristics of the 27main tributaries in the TGRC. Appendix 2. Taxa list of macroinvertebrates in the 27 main tributaries in the TGRC. (DOCX $50 \mathrm{~kb}$ )

\section{Abbreviations}

Aquatic insects\%: The percentage of individuals of aquatic insects; Baetidae\%: The percentage of individuals in baetidae taxa; Caenidae\%: The percentage of individuals in caenidae taxa; Chironomidae\%: The percentage of individuals in chironomidae taxa; Ephemerellidae\%: The percentage of individuals in ephemerellidae taxa; EPT\%: The percentage of individuals in ephemeroptera, plecoptera and trichoptera taxa; Heptageniidae\%: The percentage of individuals in heptageniidae taxa; Hydropsychidae\%: The percentage of individuals in hydropsychidae taxa; ISA: Indicator species analysis; molluscs\%: the percentage of individuals of molluscs; MRPP: Multi-response permutation procedures; NMDS: Non-metric multidimensional scaling; TGD: Three gorges dam; TGRC: Three gorges reservoir catchment; Tipulidae\%: The percentage of individuals in tipulidae taxa

\section{Acknowledgments}

The authors thank Aiming Zhu and Hongjun Wang for field assistance.

Funding

The National Natural Science Foundation of China (Nos. 51409178 and 51509169) and the Special Funds for Public Industry Research Projects of the National Ministry of Water Resources (Nos. 201401020 and 201501030).

Availability of data and materials Not applicable.

\section{Authors' contributions}

SYC carried out field experiments and wrote the manuscript; SXL collected samples of macroinvertebrates in the TGRC; SC identified the samples of macroinvertebrates in the TGRC; MXC, JXZ and JXH analyzed and interpreted the results. All authors read and approved the final manuscript.

Ethics approval and consent to participate

Not applicable.

Consent for publication

Not applicable.

\section{Competing interests}

The authors declare that no conflict of interest exists in the submission of this manuscript, and manuscript is approved by all authors for publication. I declare, on behalf of my co-authors, that the work described is original research that has not, in whole or in part, been previously published and is not under consideration for publication elsewhere. All listed authors have approved the manuscript.

\section{Publisher's Note}

Springer Nature remains neutral with regard to jurisdictional claims in published maps and institutional affiliations.

Received: 6 March 2017 Accepted: 9 August 2017

Published online: 29 August 2017

\section{References}

1. Davis S, Golladay SW, Vellidis G, Pringle CM. Macroinvertebrate biomonitoring in intermittent coastal plain streams impacted by animal agriculture. J Environ Qual. 2003:32:1036-43.

2. Maloney $\mathrm{KO}$, Feminella JW. Evaluation of single-and multi-metric benthic macroinvertebrate indicators of catchment disturbance over time at the Fort Benning Military Installation, Georgia, USA. Ecol Indic. 2006;6:469-84.

3. Joshi PC, Negi RK, Negi T. Seasonal variation in benthic macro-invertebrates and their correlation with the environmental variables in a freshwater stream in Garhwal region (India). Life Sci J. 2007:4:85-9.

4. Leunda PM, Oscoz J, Miranda R, Ariño AH. Longitudinal and seasonal variation of the benthic macroinvertebrate community and biotic indices in an undisturbed Pyrenean river. Ecol Indic. 2009;9:52-63.

5. Álvarez-Cabria M, Barquín J, Antonio JJ. Spatial and seasonal variability of macroinvertebrate metrics: Do macroinvertebrate communities track river health? Ecol Indic. 2010;10:370-9. 
6. Šporka F, Vlek HE, Bulánková E, Krno IJ. Influence of seasonal variation on bioassessment of streams using macroinvertebrates. Hydrobiologia. 2006; 556:543-55.

7. Halwas KL, Church M, Richardson JS. Benthic assemblage variation among channel units in high-gradient streams on Vancouver Island, British Columbia. J N Am Benthol Soc. 2005;24:478-94.

8. Pires A, Cowx I, Coelho M. Benthic macroinvertebrate communities of intermittent streams in the middle reaches of the Guadiana Basin (Portugal). Hydrobiologia. 2000;435:167-75.

9. Clenaghan C, Giller P, O'halloran J, Hernan R. Stream macroinvertebrate communities in a conifer-afforested catchment in Ireland: relationships to physico-chemical and biotic factors. Freshw Biol. 1998:40:175-93.

10. Rempel LL, Richardson JS, Healey MC. Macroinvertebrate community structure along gradients of hydraulic and sedimentary conditions in a large gravel-bed river. Freshw Biol. 2000;45:57-73.

11. Lenat DR. Water quality assessment of streams using a qualitative collection method for benthic macroinvertebrates. J N Am Benthol Soc. 1988;7:222-33.

12. Reece PF, Reynoldson TB, Richardson JS, Rosenberg DM. Implications of seasonal variation for biomonitoring with predictive models in the Fraser River catchment, British Columbia. Can J Fish Aquat Sci. 2001;58:1411-7.

13. Gabriels W, Lock K, De Pauw N, Goethals PL. Multimetric Macroinvertebrate Index Flanders (MMIF) for biological assessment of rivers and lakes in Flanders (Belgium). Limnol Ecol Manag Inland Waters. 2010;40:199-207.

14. Irvine K. Classifying ecological status under the European Water Framework Directive: the need for monitoring to account for natural variability. Aquat Conserv Mar Freshwat Ecosyst. 2004;14:107-12.

15. Tumwesigye C, Yusuf SK, Makanga B. Structure and composition of benthic macroinvertebrates of a tropical forest stream, River Nyamweru, western Uganda. Afr J Ecol. 2000;38:72-7.

16. Harrison $\mathrm{A}$, Hynes $\mathrm{H}$. Benthic fauna of Ethiopian mountain streams and rivers. Archiv fuer Hydrobiologie 1988; Supplement 81: 1-36.

17. Mathooko J, Mavuti K. Composition and seasonality of benthic invertebrates, and drift in the Naro Moru River, Kenya. Hydrobiologia. 1992;232:47-56.

18. Hynes J. Annual cycles of macro-invertebrates of a river in southern Ghana. Freshw Biol. 1975;5:71-83.

19. Cowan C, Oswood M. Spatial and seasonal associations of benthic macroinvertebrates and detritus in an Alaskan subarctic stream. Polar Biol. 1984;3:211-5.

20. Outridge P. Seasonal and spatial variations in benthic macroinvertebrate communities of Magela Creek, Northern Territory. Mar Freshwater Res. 1988; 39:211-23.

21. O'Connor N, Lake P. Long-term and seasonal large-scale disturbances of a small lowland stream. Mar Freshw Res. 1994;45:243-55.

22. Jacobsen $D$, Encalada A. The macroinvertebrate fauna of Ecuadorian highland streams in the wet and dry season. Arch Hydrobiol. 1998;142:53-70.

23. Mathis BJ, Dorris TC. Community structure of benthic macroinvertebrates in an intermittent stream receiving oil field brines. Am Midl Nat. 1968;80:428-39.

24. Miller MC, Stout M. Variability of macroinvertebrate community composition in an arctic and subarctic stream. Hydrobiologia. 1989:172:111-27.

25. Flecker AS, Feifarek B. Disturbance and the temporal variability of invertebrate assemblages in two Andean streams. Freshw Biol. 1994;31:131-42.

26. Arunachalam M, Nair KM, Vijverberg J, Kortmulder K, Suriyanarayanan H. Substrate selection and seasonal variation in densities of invertebrates in stream pools of a tropical river. Hydrobiologia. 1991;213:141-8.

27. Boulton AJ, Peterson CG, Grimm NB, Fisher SG. Stability of an aquatic macroinvertebrate community in a multiyear hydrologic disturbance regime. Ecology. 1992;73:2192-207.

28. Kay W, Smith M, Pinder A, McRae J, Davis J, Halse S. Patterns of distribution of macroinvertebrate families in rivers of north-western Australia. Freshw Biol. 1999:41:299-316.

29. Burgherr P, Ward J. Longitudinal and seasonal distribution patterns of the benthic fauna of an alpine glacial stream (Val Roseg, Swiss Alps). Freshw Biol. 2001;46:1705-21.

30. Scheibler EE, Claps MC, Roig-Juñent SA. Temporal and altitudinal variations in benthic macroinvertebrate assemblages in an Andean river basin of Argentina. J Limnol. 2014;73:76-91.

31. Mariana L. Interannual and seasonal variability of macroinvertebrates in monsoonal climate streams. BrazArch Biol Technol. 2012:55:403-10.

32. Leung AL, Li AOY, Dudgeon D. Scales of spatiotemporal variation in macroinvertebrate assemblage structure in monsoonal streams: the importance of season. Freshw Biol. 2012;57:218-31.
33. Fang $H$, Zhang $F$, Zhang $M$, Chen $H$, Li H, Liu Z. Community Structure of Macrozoobenthos and Biological Evaluation of Water Quality in Yuanhe River of Ganjiang River Basin (In Chinese). J Anhui Agric Sci. 2011;39:2254-7.

34. Li B, Zhang Y, Wang Z. Longitudinal and Seasonal Variation of the Benthic Macroinvertebrate Community of the Nu River in Yunnan Province (In Chinese). J Southwest China Norm Univ(Nat Sci). 2011;36:138-43.

35. Liu H, Ye S, Yang X, Zhang L, Zhong G, He Y, Li Z. Spatio-temporal dynamics of aquatic organism community and their relationships to environment in Niyang River,Tibet:3.macrozoobenthos (In Chinese). J Lake Sci. 2014;26:154-60.

36. Liu S, Chen D. Dynamic Changes of Zoobenthos in Laojianghe Oxbow and Its Fishery Utilization (In Chinese). J Hubei Agric Coll. 1999:31-4.

37. Yang Q, Chen Q, Han R. Community structure analysis of macroinvertebrate in the Lijiang River(In Chinese). Freshw Fish. 2011:41:91-5.

38. Zhao Q, Gao X, Zhang Y, Zhao R, Ding S, Liu S. Study on Spatial and Temporal Distributions of Macroinvertebrate Communities in Hongshui River,Guangxi Province(In Chinese). Res Environ Sci 2014; 27: 1150-1156.

39. Chen Y, Li S, Zhang Y, Zhang Q. Assessing soil heavy metal pollution in the water-level-fluctuation zone of the Three Gorges Reservoir, China. J Hazard Mater. 2011;191:366-72.

40. Chi S, Hu J, Li M, Zheng J. Developing a baseline and tools for the future assessment of the ecological status of rivers within the Three Gorges Reservoir catchment, China. Hydrobiologia. 2016;755:185-96.

41. Yan T, Yang L, Campbell CD. Microbial biomass and metabolic quotient of soils under different land use in the Three Gorges Reservoir area. Geoderma. 2003;115:129-38.

42. Reynoldson TB, Rosenberg DM, Resh VH. Comparison of models predicting invertebrate assemblages for biomonitoring in the Fraser River catchment, British Columbia. Can J Fish Aquat Sci. 2001;58:1395-410.

43. João Feio M, Reynoldson TB, Graça MA. Effect of seasonal changes on predictive model assessments of streams water quality with macroinvertebrates. Int Rev Hydrobiol. 2006:91:509-20.

44. Findik Ö. Spatial and seasonal distribution of macroinvertebrates in high altitude reservoir (Beyler Reservoir, Turkey). Chin J Oceanol Limnol. 2013;31: 994-1001.

45. Rundle S, Attrill M, Arshad A. Seasonality in macroinvertebrate community composition across a neglected ecological boundary, the freshwater-estuarine transition zone. Aquat Ecol. 1998:32:211-6.

46. McCune B, Grace JB, Urban DL, Analysis of ecological communities. Vol. 28. MjM software design Gleneden Beach. Oregon. 2002;

47. Snyder CD, Young JA, Lemarié DP, Smith DR. Influence of eastern hemlock (Tsuga canadensis) forests on aquatic invertebrate assemblages in headwater streams. Can J Fish Aquat Sci. 2002;59:262-75.

48. Heino J, Muotka T, Mykrä H, Paavola R, Hämäläinen H, Koskenniemi E. Defining macroinvertebrate assemblage types of headwater streams: Implications for bioassessment and conservation. Ecol Appl. 2003;13: 842-52.

49. Zar JH, Biostatistical analysis. 1999: Prentice Hall. 797-9.

50. Ward JV, Dufford RG. Longitudinal and seasonal distribution of macroinvertebrates and epilithic algae in a Colorado springbrook-pond system. Arch Hydrobiol. 1979;86:284-321.

51. Brewin P, Buckton S, Ormerod S. The seasonal dynamics and persistence of stream macroinvertebrates in Nepal: do monsoon floods represent disturbance? Freshw Biol. 2000;44:581-94.

52. Qiu G, Hu S, Ye D, Yuan L, Zang X. Investigation on the present situation of eutrophication and water bloom in the branches of three gorges reservoir(In Chinese). Resources Environ Yangtze Basin. 2011;20:311-6.

53. Qiu G. General investigation of eutrophication for tributaries in TGP reservoir area(In Chinese). Yangtze River. 2008;39:1-4.

54. Bêche LA, Mcelravy EP, Resh VH. Long-term seasonal variation in the biological traits of benthic-macroinvertebrates in two Mediterranean-climate streams in California, USA. Freshw Biol. 2006:51:56-75.

55. Bêche LA, Resh $V H$. Short-term climatic trends affect the temporal variability of macroinvertebrates in California 'Mediterranean'streams. Freshw Biol. 2007;52:2317-39.

56. Johnson RC, Carreiro MM, Jin HS, Jack JD. Within-year temporal variation and life-cycle seasonality affect stream macroinvertebrate community structure and biotic metrics. Ecol Indic. 2012:13:206-14.

57. Murphy JF, Giller PS. Seasonal dynamics of macroinvertebrate assemblages in the benthos and associated with detritus packs in two low-order streams with different riparian vegetation. Freshw Biol. 2000;43:617-31. 
58. Zaiha NA, Mohd IMS. Salmiati. Temporal Distribution of Benthic Macroinvertebrate Communities from Tropical Forest Stream in Gunung Pulai Recreational Forest, Johor, Peninsular Malaysia. Sains Malaysiana. 2015; 44:1223-8.

59. Robinson C, Tockner K, Burgherr P. Seasonal patterns in macroinvertebrate drift and seston transport in streams of an alpine glacial flood plain. Freshw Biol. 2002;47:985-93.

60. Linke S, Bailey RC, Schwindt J. Temporal variability of stream bioassessments using benthic macroinvertebrates. Freshw Biol. 1999;42:575-84.

61. Zamora-Muñoz C, Sáinz-Cantero CE, Sánchez-Ortega A, Alba-Tercedor J. Are biological indices BMPW'and ASPT'and their significance regarding water quality seasonally dependent? Factors explaining their variations. Water Res. 1995;29:285-90.

62. Clarke RT, Hering D. Errors and uncertainty in bioassessment methods-major results and conclusions from the STAR project and their application using STARBUGS. Hydrobiologia. 2006;566:433-9.

63. Gíslason GM, Hansen I, Ólafsson JS, Svavarsdóttir K. Longitudinal changes in macroinvertebrate assemblages along a glacial river system in central Iceland. Freshw Biol. 2001;46:1737-51.

64. Gibbins C, Dilks C, Malcolm R, Soulsby C, Juggins S. Invertebrate communities and hydrological variation in Cairngorm mountain streams. Hydrobiologia. 2001;462:205-19.

Submit your next manuscript to BioMed Central and we will help you at every step:

- We accept pre-submission inquiries

- Our selector tool helps you to find the most relevant journal

- We provide round the clock customer support

- Convenient online submission

- Thorough peer review

- Inclusion in PubMed and all major indexing services

- Maximum visibility for your research

Submit your manuscript at www.biomedcentral.com/submit
Biomed Central 